\title{
Modelling of the ferritic stainless steel grade 430 bolted connections with damage implementation
}

\author{
K.P. Sobrinho, A.T. Silva, M.C. Rodrigues, P.C.G.S. Vellasco \& L.R.O. Lima \\ State University of Rio de Janeiro, Rio de Janeiro, Brazil \\ J. Henriques \\ Construction Engineering Research Group, Faculty of Engineering Technology, Hasselt University, Hasselt, \\ Belgium
}

\begin{abstract}
This paper presents the calibration of a numerical model to simulate bolted connections using a damage criterion for ductile materials. The motivation for this investigation is related to the difficulties in obtaining the ultimate load in connections with large deformations using a simple static analysis. The analyzed models consist of bolted connections made of the stainless steel grade 430 with a single bolt under double shear, where the weak part is located in the internal plate. A comparison of the results with the performed experimental tests made possible to check the efficiency of the developed model. The obtained results indicated a good correlation, both in terms of maximum load and associated failure modes, between the simulated and tested bolted connections.
\end{abstract}

\section{INTRODUCTION}

In recent years, a significant increase in the use of stainless steel in structures has been observed. This is directly related to the increase in research regarding its structural performance, including at the microstructural level. The analysis of the material's behavior by means of computational tools is one of the field of interests, as it makes possible to evaluate and exploit the material until its rupture, for example, the realization of collision simulations (Levanger, 2012). In certain situations, stainless steel was already widely used, since this material contains several properties that can provide advantages when compared to carbon steel. Some of these advantages may be pointed out such as: corrosion, high temperatures and impact resistances, recycled capacity and ductility (Baddoo, 2008). However, when a cost analysis is carried out without considering the life-cycle, due to the high initial cost of stainless steel, the material becomes uneconomical. For a correct comparison, it is necessary to consider the properties of the material and their impact in overall cost of construction beyond the intial cost (Gedge, 2008). Another important factor contributing to the cost reduction in the application is related to the structural design recommendations. The current codes and standards for design of stainless steel structures have equations analogous to carbon steel which are often conservative, as these do not consider the actual capacity of the material.

The modelling of structural members and connections with the finite element method is essential for research and requires a proper correlation of the numerical model with experiments. However, when the analyses involve mechanical problems with contact and subject to large deformations, as in stainless steel bolted connections, it is often not possible to calibrate the numerical model up to the ultimate load and associated deformation using traditional 
a)

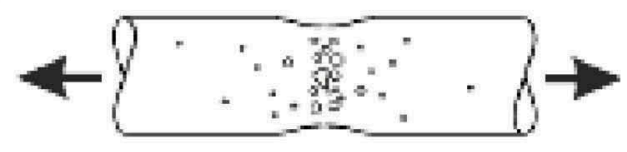

b)

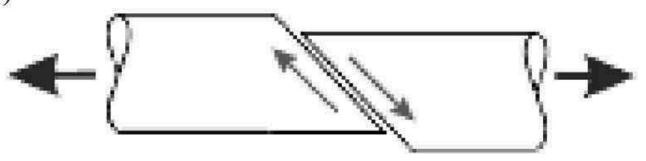

Figure 1. Ductile fracture of metals. a) void nucleation, coalescence and growth; b) shear band localization.

nonlinear analyses. The simulation of bolted connections subjected to large deformations often leads to convergence difficulties.

This paper is devoted to the modelling of stainless steel bolted connections, in the large deformation field, using a damage criteria. Experimental results of ferritic stainless steel 430 bolted connections subject to double shear were used to verify the assumptions adopted in the numerical modelling. This type of connection is of particular interest as it combines material, with high deformation capacity, with the complexity of bolted connections using thin-plate under high-stress concentrations near the bolt hole. A rupture criterion was required to be implemented in the finite element model despite the limitations on the available material mechanical properties, as it is often the case of material characterization consisting of only tensile tests (Dzugan, 2012). The use of a ductile material damage criterion allows the simulation of the behaviour of bolted connections and includes the determination of its structural capacity after the peak load (Lyu et al., 2019).

The Abaqus Finite Element Analysis (FEA) software has been used to simulate the material rupture. This granular material failure can be modelled by the ductile fracture of materials or by necking instability (Abaqus, 2005). The first strategy, used in this article, can occur through the nucleation of voids, where they coalesce and grow until they form the localized tightening (necking), or through the location of a cut band, as shown in Figure 1.

The numerical modelling will be presented, focusing on the implementation of the damage criterion for ductile materials applied to two stainless steel bolted connections. First, a simulation of the material characterization test is accompleshid to calibrate and validate the use of the referred criterion. Then, the results of the simulated connections are compared with experiments to further validate the developed numerical models. The performed experimental program used to calibrate the numerical simulations will be presented in the next section.

\section{EXPERIMENTAL PROGRAM}

\subsection{Coupon test}

The experimental study was made at the Civil Engineering Laboratory of the State University of Rio de Janeiro - Brazil. Two coupons were tested for characterizing the adopted ferritic steel grade 430 , with a measured density of $7.67 \mathrm{mg} / \mathrm{m}^{3}$. These tests were performed on an Instron 3382, which uses an embedded data acquisition system, Bluehill 3. As for redundancy, a clip gauge was used to measure the deformation up to $5 \%$. This test layout is shown in Figure 2 as well as the obtained stress-strain curves. The characterization tests followed the recommendations prescribed by Huang \& Young (2014).

\subsection{Bolted connection tests}

The bolted connection tests were performed on a $600 \mathrm{kN}$ Losenhausen testing system while the data was acquired with the HBM Quantum X-MX1615B system, Figure 3 (a). Two bolted connections tests were carried out made of three ferritic steel plates of the same thickness connected by a high strength carbon steel bolt to induce the failure of the inner plate. This configuration does not allow the curling effect to occur, a phenomenon 
a)

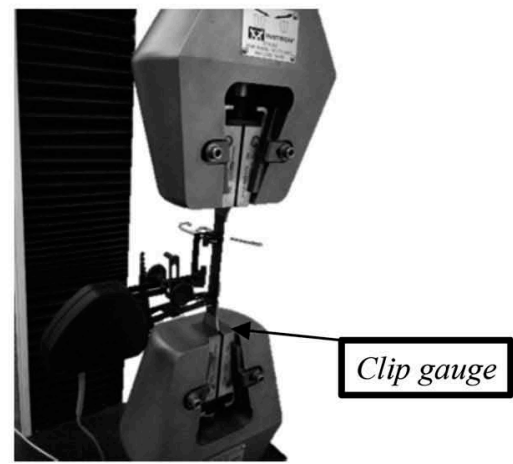

b)

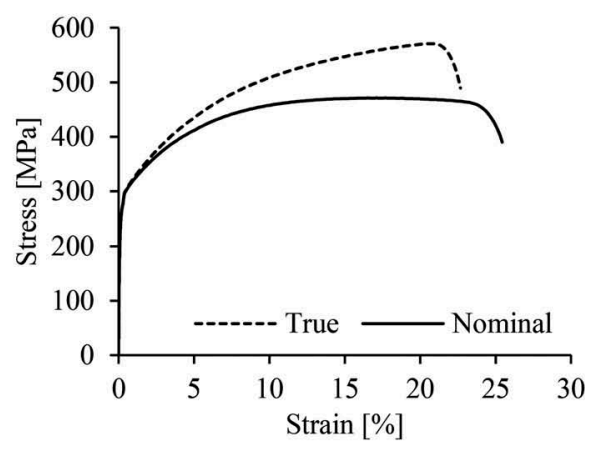

Figure 2. Coupon testing. a) Instron 3382 universal testing test machine. b) true and nominal stress-strain curves.

a)

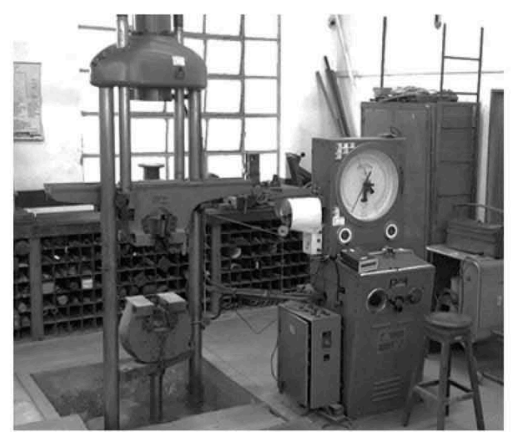

b)
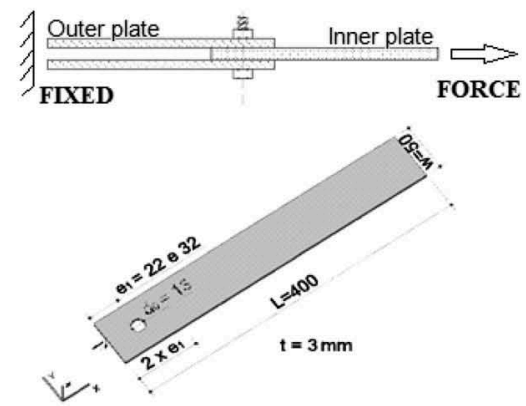

Figure 3. Experimental test setup a) universal tensile testing system. b) Specimens Geometry.

capable of influencing the behaviour of bolted connections, that could even reduce its ultimate capacity (Kim, 2011). Figure 3(b) shows a schematic configuration of the plate as well as the used geometric parameters. The nominal dimension was: $400 \mathrm{~mm} \times 50 \mathrm{~mm}$ x $3 \mathrm{~mm}$ while the adopted $\mathrm{e}_{1}$ values were $22 \mathrm{~mm}$ and $32 \mathrm{~mm}$, with the objective of inducing the bearing failure mode.

\section{NUMERICAL MODEL}

\subsection{Damage criteria}

The model analysis with damage criterion is characterized as an extremely nonlinear problem since the damage evolution is directly associated with large plastic deformations. Additionally, it is necessary to use advanced tools to enable the simulation of the material internal degradation.

The Finite Element Method (FEM) is an important mathematical tool for solving solid deformation problems. The great effectiveness of this method is related to the ability to satisfy equations that characterises the problem through interpolation functions from finite elements which in turn come from the discretization of a more complex integration space. Therefore, the FEM is characterised, basically, in three stages: i) integral formulation of the problem; ii) discretization of the problem and iii) solving the system of equations that result from the previous two steps (Reis, 2009). 
The Abaqus FEA software is a powerful finite element analysis tool where version 6.14 was used in this study. To simulate the behaviour of the analyzed connections, the dynamic explicit solver was used. In order to eliminate dynamics effects, an quasi-static analysis was performed. Since the modelling of a quasi-static problem in its natural time would require a long time to complete the analysis, it is essential to reduce the processing time of the analysis without compromising the accuracy of the solution. The model calibration in the explicit analysis was through Mass Scaling, which artificially increases the density of the material. This guarantees the use of an artificial time increase of the model, which results in a drastic reduction in processing time without compromising its accuracy.

The ductile damage with damage evolution criterion was used to assess the model rupture. This criterion requires the use of a curve that relates the deformation at the beginning of the fracture with the triaxial stress. The modelling of the material to the damage requires the definition of four parameters, which are presented below, whose points are outlined in Figure 4.

1. Material behaviour without the damage defined by points ABCD';

2. The damage initialization criterion, point $\mathrm{C}$;

3. The damage evolution curve defined by points C and D';

4. The element removal when its stiffness is compromised.

The variable $\mathrm{D}$ corresponds to the general damage value, $0 \leq \mathrm{D} \leq 1$, with the value zero being the virgin material, free from damage, and the value one when the volume element splits into two parts. Therefore, variable D characterises the level of material damage. After the damage starts, the tension tensor in the material is given by Equation 1:

$$
\sigma=(1-D) \bar{\sigma}
$$

where $\bar{\sigma}$ is the theoretical stress of the material in the absence of damage.

Point c, depicted in Figure 4, is obtained through the fracture strain versus stress triaxiality curve. These values were defined based on the studies carried out by Wierzbicki and Werner [1998], Bao [2004] and validated by Wang [2006].

The c-d curve shown in Figure 4, on the other hand, defines the damage evolution, which can be defined by a tabular softenig, damage variable versus displacement. When the damage variable is set to 1 , the corresponding element is removed. The values entered in the Abaqus program (2014), where the model calibration for a $3 \mathrm{~mm}$ finite element mesh are shown in Table 1. Further details regarding the model validation are presented in the next section.

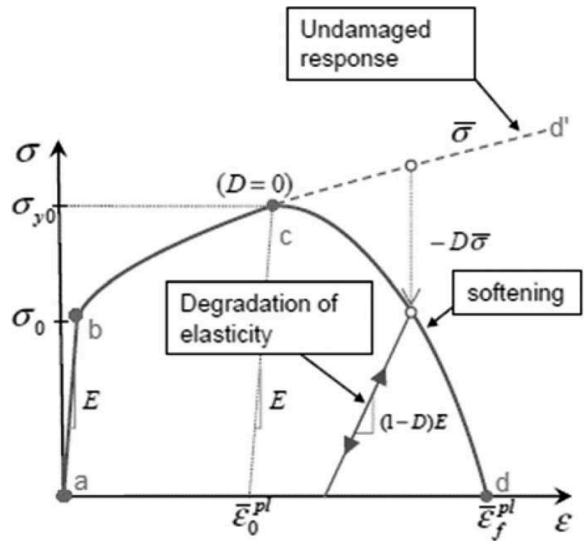

Figure 4. Schematic representation of elastic-plastic material with progressive damage. 
Table 1. Damage evolution.

\begin{tabular}{ll}
\hline Damage variable & Displacement \\
\hline 0.0 & 0.0 \\
0.8 & 0.5 \\
1.0 & 0.8 \\
\hline
\end{tabular}

a)

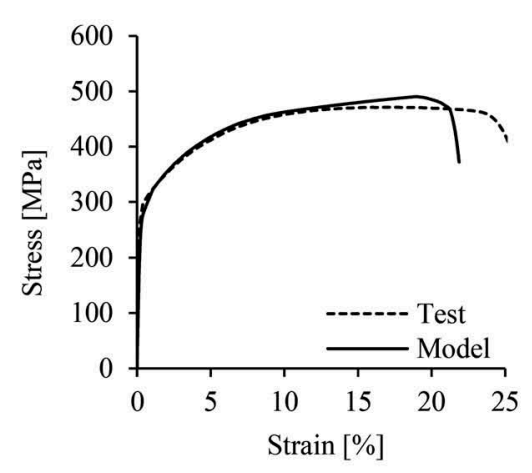

b)

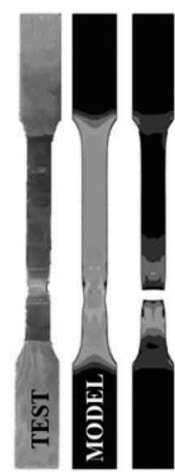

c)

$\begin{array}{ll}\begin{array}{l}\text { Yield Stress } \\ {[\mathrm{MPa}]}\end{array} & \begin{array}{l}\text { Plastic Strain } \\ {[\mathrm{mm} / \mathrm{mm}]}\end{array} \\ 28.70839 & 0.000000 \\ 109.2258 & 0.000272 \\ 203.4104 & 0.000813 \\ 326.9452 & 0.010616 \\ 402.4768 & 0.035280 \\ 502.4747 & 0.093999 \\ 546.4353 & 0.148300 \\ 567.7084 & 0.193507 \\ 570.7099 & 0.206057\end{array}$

Figure 5. Material characterization parameters: a) stress versus strain curve, b) deformation, c) true stress - true strain.

\subsection{Validation}

Initially, the model was calibrated for the tensile coupon tests where it was possible to define all parameters for configuring the adopted damage model. Figure 5 presents a comparison between the characterization curve obtained in the experiments with the numerical response. Therefore, the deformed specimen and the true stress versus true strain points used in the finite element model are also presented.

The coupon tension test model presented a good correlation with the experimental characterization tests. This allows proceeding to the next step to verify the calibration of the numerical model with the implementation of damage in the ferritic stainless steel bolted connections tests.

Figure 6 presents a comparison between the load versus displacement curves for connections with $\mathrm{e}_{1}$ values of $22 \mathrm{~mm}$ and $32 \mathrm{~mm}$, respectively. The deformed numerical models and experimental tests are illustrated in Figure 7. With these results, it can be concluded that the

a)

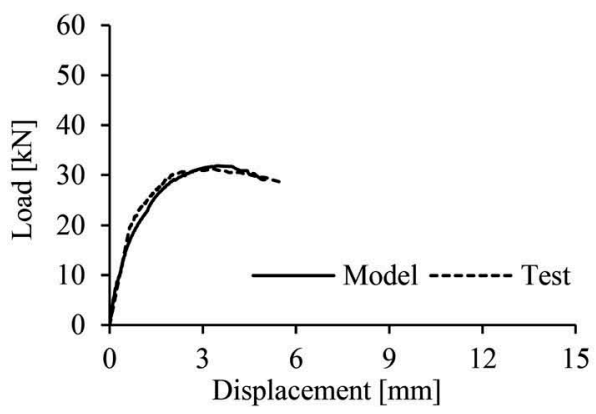

b)

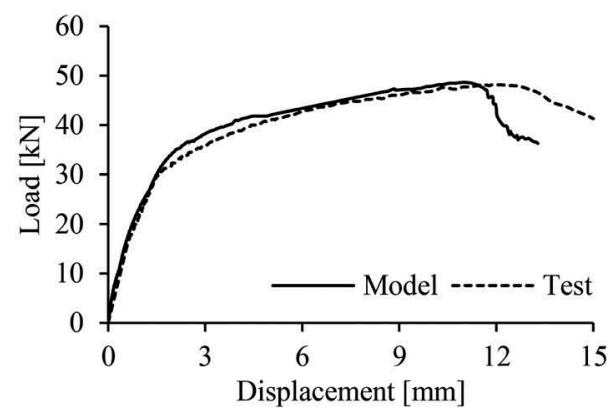

Figure 6. Load versus axial displacement curves. a) $\mathrm{e}_{1}=22 \mathrm{~mm}$; b) $\mathrm{e}_{1}=32 \mathrm{~mm}$. 
a)

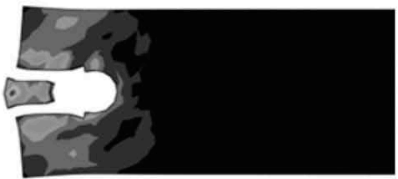

c)

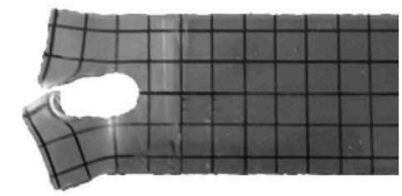

b)

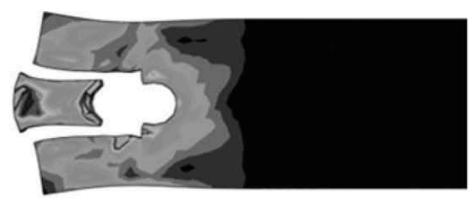

d)

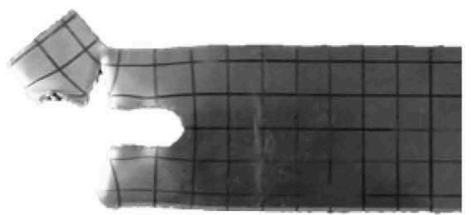

Figure 7. Deformed tested connections. a) $\mathrm{e}_{1}=22 \mathrm{~mm}$; b) $\mathrm{e}_{1}=32 \mathrm{~mm}$; c) $\mathrm{e}_{1}=22 \mathrm{~mm}$; d) $\mathrm{e}_{1}=32 \mathrm{~mm}$.

numerical modelling with the implementation of damage can be used to model the behaviour of bolted connections until their fracture. The model is also able to determine the connection failure mode. By simulating the failure of its connections, it is even possible to assess the overall behaviour of the structure (Gomes, 2017).

\section{CONCLUSIONS}

The work presented in this paper is part of an ongoing research on bolted connections using stainless steel conducted by the authors. It is recognized the high deformation of these connections due to material behavior, and depending of the stainless steel type (e.g. Austenitic), coupled with significant strain hardening. In order to improve current design methods for such connections, which are based on analogies with those for carbon steel, it is important the use of numerical models to complement the limitations of the experimental campaigns by means of parametric studies. Thus, this paper presents part of the validation process of a numerical model implementing the material damage able to reproduce the behavior of bolted connections using stainlesssteel and entering in the large deformation field. These are there-fore complex numerical simulations but necessary to adequately reproduce the mechanics of the referred connections.

Specifically, the objective of this paper was to characterise the bearing failure mode using a numerical model implementing the damage criterion for ductile materials. The behaviour of bolted connections of ferritic stainless steel 430 was evaluated for plates in double shear and $\mathrm{e}_{1}$ values of $22 \mathrm{~mm}$ and $32 \mathrm{~mm}$. The calibration of numerical models was performed by comparison with experiments. Initially, the material characterization model was performed, where it was possible to define all the damage parameters. This was followed by the connection evaluation through the load versus axial displacement curves, as well as their failure modes. Based on the results presented, it was possible to conclude that the numerical models were able to represent the bearing failure mode, a ratio between the ultimate numerical and experimental test load of 1.02 and 1.01 for connections with $\mathrm{e}_{1}$ values of $22 \mathrm{~mm}$ and $32 \mathrm{~mm}$, respectively, was obtained. On the other hand, the quality of the simulations to capture the ultimate deformation of the tested specimens decreases. Though, some improvement of the numerical model can still be envisaged, the simulation in the large deformation field is complex and highly dependent of the microscopic structure of the material.

\section{ACKNOWLEDGMENTS}

The authors would like to thank CAPES (Finance code 001), CNPq (306042/2013-4; 305026/ 2017-8), FAPERJ and CERG for the financial support to this research program. 


\section{REFERENCES}

Abaqus. 2005. Abaqus/Explicit. Advanced Topics. Lecture 9: Material Damage and Failure.

Abaqus/ CAE. 2014. Theory Reference. SIMULIA - Inc. [S.l.]. 6.14-5.

Baddoo, N. R. 2008. Stainless steel in construction: A review of research, applications, challenges and opportunities. Journal of Constructional Steel Research 64 (11): 1199-1206.

Bao, Y. Wierzbicki, T. 2004. A comparative study on various ductile crack formation criteria. Journal of Engineering Materials and Technology 126: 314-324.

Dzugan, J., Spaniel, M., Konopík, P., Ruzicka, J., Kuzelka, J. 2012. Identification of Ductile Damage Parameters for Austenitic Steel. World Academy of Science, Engineering and Technology. International Journal of Mechanical and Mechatronics Engineering6 (5): 6.

Gedge, G. 2008. Structural uses of stainless steel - buildings and civil engineering. Journal of Constructional Steel Research 64(11): 1194-1198.

Gomes, V. R. 2017. Análise da influência de ligações semirrígidas na robustez de pórticos metálicos. MSc Dissertation, PGECIV - Civil Engineering Graduate Program. Rio de Janeiro: State University of Rio de Janeiro, p. 141. (In Portuguese).

Huang, Y; Young, B. 2014. The Art of Coupon Tests. Journal of Constructional Steel Research 96: $159-175$.

Kim, T. S.; Kuwamura, H. 2011. Numerical investigation on strength design and curling effect of mechanically fastened joints in cold-formed austenitic stainless steel. Materials and Design 32: 3942-3956.

Levanger, H. 2012. Simulating ductile fracture in steel using the finite element method comparison of two models for describing local instability due to ductile fracture. MSc Dissertation, Norway: Faculty of Mathematics and Natural Sciences University of Oslo, p.135.

Lyu,Y.; Wang,Y.; Li, G.; Jiang,J. 2019. Numerical analysis on the ultimate bearing resistance of single-bolt connection with high strength steels. Journal of Constructional Steel Research 153: 118-129.

Reis, F. J. P. 2009. Fractura em metais dúcteis - modelação numérica do dano em metais dúcteis. $M S c$ Dissertation. Faculdade de Engenharia, Universidade do Porto.(In Portuguese).

Wang K. 2016. Calibration of the Johnson-Cook failure parameters as the chip separation criterion in the modelling of the orthogonal metal currint process. Master Thesis. Hamilton: McMaster University.

Wierzbicki, T. Werner, H. 1998. Cockroft and Latham Revisited. Impact \& Crashworthiness Laboratory Report:16. 